\title{
The development of the architectural form of a tower derived from a traditional and philosophical symbol, realized by solutions of high-class technologies. The case of the Bitexco Financial Tower
}

\author{
Tran Van $\mathrm{Khai}^{1, *}$ \\ ${ }^{1}$ Van lang University, 45 Nguyen Khac Nhu, District No1, Ho Chi Minh City 700000, Vietnam
}

\begin{abstract}
The Bitexco Financial Tower, majestically standing tall in the heart of Ho Chi Minh City, Vietnam, rejects the box-shaped, abstract forms of modernism, incorporating an innovative idea of contemporary architecture. Based on the inspiration from the Bitexco Group, a renowned architect designedthe tower that became an iconic landmark of the city in the form of a lotus bud, one of the most iconic symbols of Vietnamese culture since ancient times. High class structural system solution designed by top international professional teams enable the building to rise high with its graceful, statuesque design of the lotus flower shape. CNNGo recently ranked the Bitexco Financial Tower fifth in their listing of the world's 20 most-iconic skyscrapers.
\end{abstract}

\section{Introduction}

When many trends of contemporary architecture turn away from the pure geometrical forms of box-shaped abstraction developed by the masters of modernism, the architects of the 21 st century are increasingly challenged to find symbolic ideas to effectively address the changing needs of a dynamic society. In this context, the developer Bitexco Group with Mr. $\mathrm{Vu}$ Quang Hoi as Chief of Board, laid down the policy for the formation of the Bitexco Financial Tower to become an iconic embodiment which represents the energy and aspirations of the Vietnamese people.

The selection of the form of a tower from traditional symbols was carried out in a broad philosophical context. Reviews show the meaning of the lotus flower, a symbol of Buddhism and enlightenment, was that the flower grows in the mud, but when it reaches the light, becomes the most beautiful flower ever, while purifying the water wherever it grows. In the imagination of the people in Vietnam, the lotus flower symbolizes beauty, and the spiritual and pure nature of ethnicity.

With AREP world-renowned architect Carlos Zapata behind the delicate lotus flower form design, Bitexco Financial Tower became memorable and iconic by encapsulating an image that symbolises the national flower of the Vietnamese people.

\footnotetext{
${ }^{*}$ Corresponding author: angela-1309.m@yandex.ru
} 
Wind-induced building sway was a major concern, as the tower is tall with a rounded lotus form while the perimeter tapers inward at the lower floors. Top international structural and construction teams partnered to meet the challenge of technological complexity of the lotus tower form. A structural system was designed using concrete cast-in-place outrigger and belt trusses which stiffen the tower against the swaying motion while cantilever beams beyond the primary girders effectively support the circular edge of the helipad which was suspended high above the ground. This was analized as the most constructible and economical structural solution in the context of the central business district of the city here. This research is intended to describe very briefly how architecture and traditional symbols and high-class structural solutions have functioned in relation to each other in a project through the dynamic expressive features of its form. In a broader philosophical context, the finding hopes to consider that the constant development of design through architectural representation with the help of high-class technologies is critical to its success, the Bitexco Financial Tower project become a true example of forward thinking and design, an unmistakably world-class presence.

\section{Literature review}

\subsection{Review of the theories of contemporary architecture on the creation of new effective design forms to address the changing needs of society}

An article with the title of: 7 things to discover about contemporary architecture, November 21, 2014/in Articles, Architecture/by BONE Structure [1] argued that: Contemporary architecture aims to break away from the processes and ways of thinking that have become standard. It is innovative. All we need to do is to look around to see that the dominant line in architecture is the straight line. Contemporary architecture tends to distance itself from this habit by opting more often for curved lines, instead. In some cases, a building is entirely designed around curved lines. This Article cited that: The main thing to remember about contemporary architecture is that it tries to distinguish itself from conventional architecture through new architectural ideas. For example, the goal of giving a building an unusual form is obviously to surprise, to astonish, and to alter perspectives. The use of volumes other than cubes makes it possible to create different interior spaces.

The Article, Architecture/by BONE Structure [1] illustrates the tendencies of contemporary architecture by the example of the Capital Gate tower in Abu Dhabi, United Arab Emirates (fig. 1) This circular, 35-story tower has an 18-degree tilt in the middle, making it the most inclined building in the world, a design by the Scottish architecture firm RMJM. Serena Love [2] cited: Furthermore, the choice of building materials and their use in architecture can be considered codes of social practice and even ideology. As material culture, architecture becomes a metaphor for human engagement and symbolic communication. Selay Yurtkuran, Gözde Kırlı and Yavuz Taneli Uludağ [3] argue that: Designers draw their inspiration from multiple sources to address challenging design problems. One method is to study nature, and attempt to comprehend the ways in which it has evolved to address environmental challenges. This practice has been coined biomimetic, a term introduced in the 1950s by Otto Schmitt. 


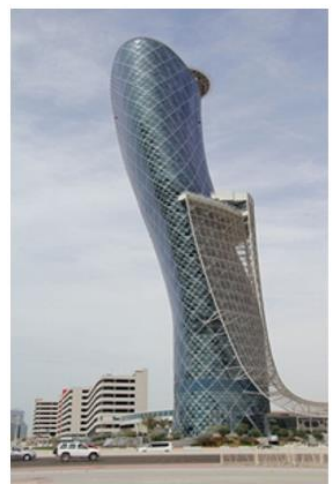

Fig. 1. Capital Gate tower in Abu Dhabi

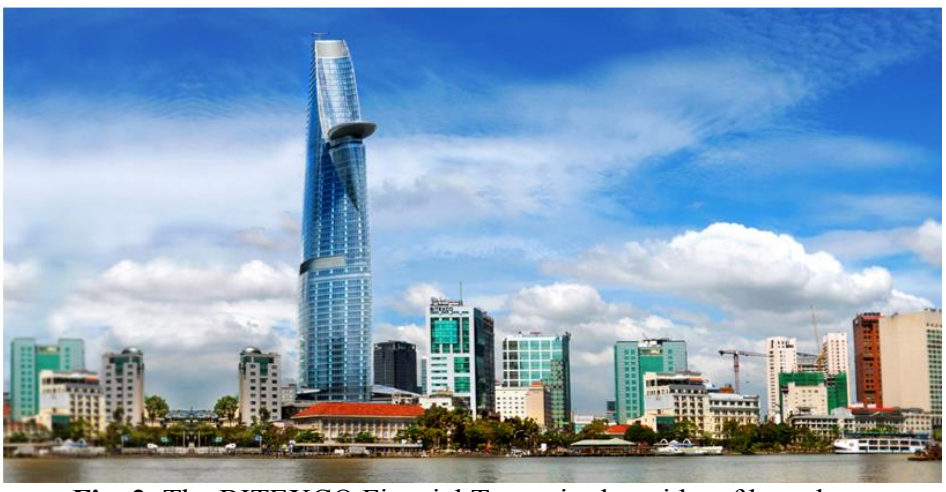

Fig. 2. The BITEXCO Finacial Tower in the midst of box shape buildings of Modern architecture in dist.1, Hochiminh City

[Source: BONE StructureNov.21.2014).

Biomimetic has increasingly been employed in architecture and engineering. Nikos A. Salingaros \& Kenneth G. Masden [4] argued that: A creative revolution is now possible, one that will transform the built environment in wonderfully human ways. A new intelligent architecture can impart a greater sense of humanity to the city and to the world.

The above research shows that the main tendencies of contemporary architecture turn away from the pure geometrical forms of box-shaped abstraction developed by modernism, and aims through studying nature to discover ways to effectively address the changing needs of the developing society.

\subsection{Review of the approaches to the symbolic form of the lotus flower}

Pedram Rezania [5] examined historyand concludesthat the lotus in the ancient East is as important as the Rose in the West, and in the 8th BC the image of lotus was transferred from Egypt into Phoenicians and then to Mesopotamia and Iran. The Phoenician goddess has lotus in her hands as the symbol of their power of creation. Rezania described that this plant was worshipped in ancient Egypt and in many parts of Asia. The holiness of the lotus goes back to its aquatic environment because the water was the ancient symbol of an old ocean, which the world was created from and the floating lotus on that was the symbol of the uterus. Since the lotus opens at the rising of the sun and closes at sunset, it seems to be like the sun.

M.A. Carrillo de Albornoz \& M.A. Fernández [6] suggested that in the Orient, this flower has various symbolic aspects. But its main characteristics stem from the fact that it blossoms on stagnant waters. This is why the lotus is seen as a symbol of purity; although blossoming on murky waters it remains immaculate. M.A. Carrillo de Albornoz \& M.A. Fernández [6] further described the characteristic of the lotus flower as: "Rising out of the darkness to blossom in full sunlight, this flower is the symbol of spiritual fulfilment. It represents manifestation that emerges on the surface of the primeval waters, like the Cosmic Egg. The closed bud contains the realization of the potential hidden in the initial seed".

Rev. Katherine Aryshta Dean [7] stated that for over 3,000 years, the Sacred Blue Lotus (actually a water lily) was used medicinally and spiritually by the priesthoods of Egypt, Greece and Rome. So important was this flower that the Egyptians dedicated a god, Nefertem, the son of Sekhmet and Ptah, to protect and care for it. The Blue Lotus, or Nymphaea Caerulea by its scientific name, was revered as a symbol of something sacred and 
holy to the ancients - and the fact that this plant was seen as a god itself is an indicator of its spiritual significance to the Egyptians.

The above discussions show that national symbols can fulfill certain unifying and divisive functions, which affect feelings of common identity. The image of the symbols could be derived from nature such as the national animal, bird, flower, fruit tree and particularly in this case the lotus flower.

\subsection{Review of the concept of the lotus as a symbol of divine beauty and the national flower of Vietnam}

Cutemintran [8] describes the role of the lotus flower in Vietnam: 'Lotus flowers play an important role and special position in both Vietnamese spirit and culture. From a long time ago up to now, lotus flowers have been in Vietnamese people's hearts, life and culture. Contemplating lotus flowers, we can see and realize images of Vietnamese people'.

The article from Administrator [9] on 28 August, 2008 describes the One Pillar Pagoda as a historic Buddhist temple in Hanoi, the capital of Vietnam. This article presented the legendary story: According to legend, ageing emperor Ly Thai To of the Ly dynasty, who had no children, used to go to pagodas to pray to Buddha for a son. One night, he dreamt that he was granted a private audience to the Bodhisattva Avalokiteshvara, who was seated on a great lotus flower in a square-shaped lotus pond on the western side of thang long citadel, and who gave the king a baby boy. Months later, when the queen gave birth to a male child, the emperor ordered the construction of a Pagoda supported by only one pillar to resemble the lotus seat of his dream in honour of the Bodhisattva Avalokiteshvara. According to one theory, the pagoda was built in the a style of a lotus emerging out of the water.

In an article concerning the lotus flower (scientific name N. nucifera) Share Siwek Share [10] said that the N. nucifera is widely naturalized. It is the national flower of Vietnam and India. Many times, the term "lotus" is applied to water lilies as well as the true lotuses, although their growing habits and uses are very different.

Pham Ha [11] in A Brief History of the Luxurious Pink Lotus, Vietnam's National Flower, Jun. 22nd, 2017 shared on Facebook and Twitter, cited that professor To Ngoc Thanh, a member of the Advisory Council on Vietnam's National Flower has answered in an interview with Labour newspaper: "As I understand, India and Sri Lanka also have their lotus chosen as national flowers, but theirs is the white lotus, while we choose our pink lotus flower. Our lotus represents the noble mind and pure spirit of Vietnamese and is the best symbol to characterize Vietnam." According to a poll organized by the Ministry of Culture, Sports and Tourism (MoCST), the lotus ranks first on the list with $71.1 \%$, out of a total 60,000 votes. Le Tien Tho [12], Deputy Minister of MoCST, clarified that the lotus was chosen because it originates from Vietnam and has been grown in most parts of the country for a long time to embody both cultural identity and national spirit. The lotus also has a pleasant fragrance and appeared in many traditional literatures, cultural and architectural works of Vietnam. Furthermore, after receiving the majority of votes for the lotus as national flower, the pink lotus was featured at another exhibition in the city of Danang).

It is clear that all the above research assumes that the Vietnamese love the lotus because it symbolizes the gracefulness, commitment and spiritual knowledge that it was regarded as Vietnam's national flower.

\subsection{Review of the of structure solutions appropriate for the tall buildings with an unconventional tube shape of the lotus flower.}

Er. Nishant Rana, Siddhant Rana [13] examines the main structure systems of the high-rise tower building and summerized that there are 4 main structural systems that have recently 
been applied for high-rise tower buildings: (1) Braced-Frame Structural System; (2) Framed Tube Structural System; (3) Outrigger-Braced Structural System, and; (4) Shear Wall Structural System. Nishant Rana and Siddhant Rana [13] also described that the 'BracedFrame Structural System' is both an efficient and economical way for improving the lateral stiffness and resistance of rigid frame system. The 'Framed Tube Structural System' evolved from a quest to develop a bracing configuration that would place as much gravity load on the exterior columns as possible to help counter the overturning effects of lateral loads while taking advantage of exterior.

Bryan Stafford Smith and Alex Coull [14] examined and described the characteristics of the 'Shear Wall Structural System' as follows: Concrete or masonry continuous vertical walls may serve both architecturally as partitions and structurally to carry gravity and lateral loading. Bryan Stafford Smith and Alex Coull found that because of their stiffness, the shear wall structural system can be economical up to 35 stories. It is especially important in the shear wall system to try to plan the wall layout so that the lateral load tensile stresses are suppressed by the gravity load stresses.

Hi Sun Choi, Leonard Joesph, and Neville Mathias [15] described the 'Outrigger-Braced Structural System' as: Outrigger are rigid horizontal structures designed to improve building overturning stiffness and strength by connecting the core or spine to distant columns. Outrigger systems function by tying together two structural systems- typically a core system and a perimeter system to yield whole structural behaviors that are much better than those of component system. Outrigger system performance is affected by outrigger locations through the height of the building, the number of levels of outrigger provided, their plan locations, outrigger truss depths and the primary structural materials used.

Catrina Grünbaum [16] stated that: The building should not get too heavy for economical and practical reasons, so it is important to find an optimal equilibrium. The heaviest structure is the one with two cores and the least heaviest is the one with trusses on the outside of the building and with the core placed in the middle, which is also the stiffest structure. This conclusion is taken from the case study.

Solutions of structural technologies for high-rise buildings are not new, but the above professionals conceptualize the advantage of the Outrigger-Braced Structural System with trusses on the outside of the building which we can conclude is more appropriate for unconventional tube shaped towers.

\section{Materials and methods}

\subsection{Materials from the project location context}

Located in the Central Business District of a City of one of the world's fastest-growing economies and strategically positioned to attract leading companies, Bitexco Financial Tower stands at the heart of Ho Chi Minh's financial centre.

In the CBD in District 1 of the city, it is carefully positioned on many urban composition axises. Situated adjacent to Nguyen Hue boulevard, it is well connected to the Thu Thiem Tunnel and two main bridges, in close proximity to the Tan Son Nhat International Airport. With this advantage in location, the tower is often chosen as the place to hold fireworks and laser display shows, the tower shines resplendent in this event, a worthy symbol of the development of the city. 


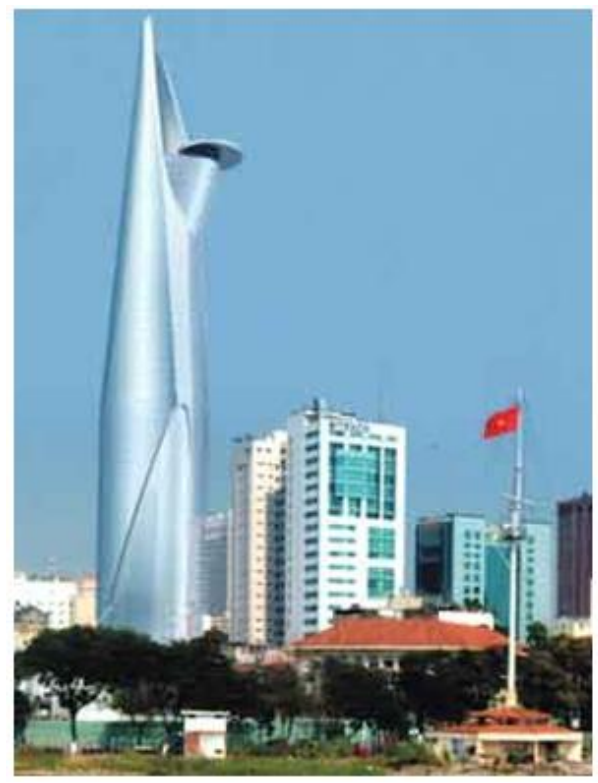

Fig. 3. Bitexco Financial Tower

[Source: Talk Vietnam]

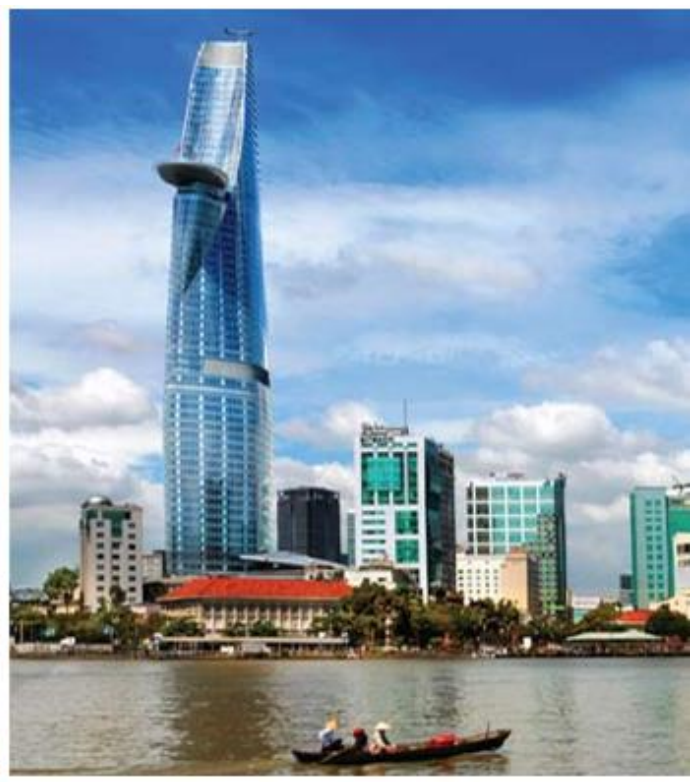

Fig. 4. Bitexco Financial Tower in the CBD

\section{[Source: Bitexco Group]}

\subsection{Materials from the required functions of the tower:}

According to the information provided from the project developer, the Bitexco Financial Tower is a mixed-use project which includes office and retail space. The tower has more than 39,000 square meters of office space, from 7 th to 64 floors, and the six-story retail podium Icon68, with around 10,000 square meters. Around 464 square meters of space is available for a casual dining restaurant on level 50 and around 568 square meters of space is used for a fine dining restaurant on level 51, as well as 300 square meters on level 52 for a VIP \& Bar Lounge. A heli-pad located on the southern side of the Bitexco Financial Tower extends 22 meters out from the main structure. The heli-pad cantilevers from the 52nd floor are strong enough to carry a helicopter under 3 tons of weight and resembles a blossoming lotus bud. It required a structural and economical structural solution.

\subsection{Methodology}

The methodology here describes the selection of the form of a tower from traditional symbols which was carried out in a broad philosophical context using both qualitative and quantitative methods, including a mixture of both as the topics discussed here comes from an architectural object that is both technology and social and the social aspect focusing on art.

Documentary analysis carried out mainly from reliable research sources is the main basis of the methods.

The qualitative methods of the article were based on the analysis of the nature of the lotus flower symbol and its possibility of its application in the design of the Bitexco Financial Tower. The quantitative methods of the article were based on an analysis of dimensions of the building, number of stories to have a broad but clear academic justification of the technological solutions. 


\section{Discussion and analysis of the design philosophy}

To critically examine how an architectural project represents its form, the significance and objective of representation must be questioned. The developer and professionals who created the Bitexco Financial tower intended that the architecture of this lotus building will be both a symbol, which represents Vietnam's vitality and its rapid development towards full global integration. Architecture must be considered for both its physical value - form, measure, scale, materiality and its poetic nature - symbolism, sign and meaning [17].

Considered as the national flower of Vietnam, the lotus represents the open, generous spirit and the beauty of the Vietnamese people. The meaning of the poetic form of the lotus in Vietnamese culture has been providing inspiration for art, literature and architecture everpresent in ceremonies. The botanical name of the lotus is Nelumbo Nucifera of the Nelumbonaceae flower family. Originating in Vietnam a long time ago, the lotus is highlyadaptive in almost all parts of the country. The lotus grows in water and has primarily pink or white flowers. It has a special position in life and culture representing the beauty of the Vietnamese soul and the Vietnamese identity. The optimistic outlook of the flower can adapt easily to any situation whilst simultaneously purifying the water wherever it grows. It is usually placed in the most spiritual area of the Vietnamese house as decoration.

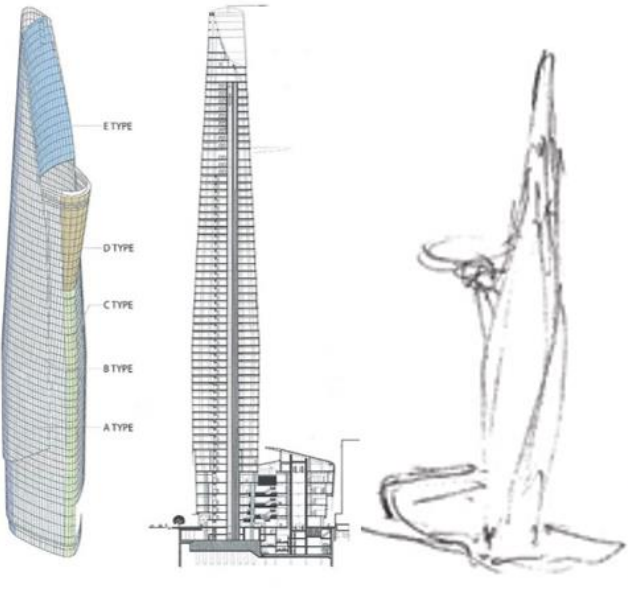

Fig. 5. Tower form and section.

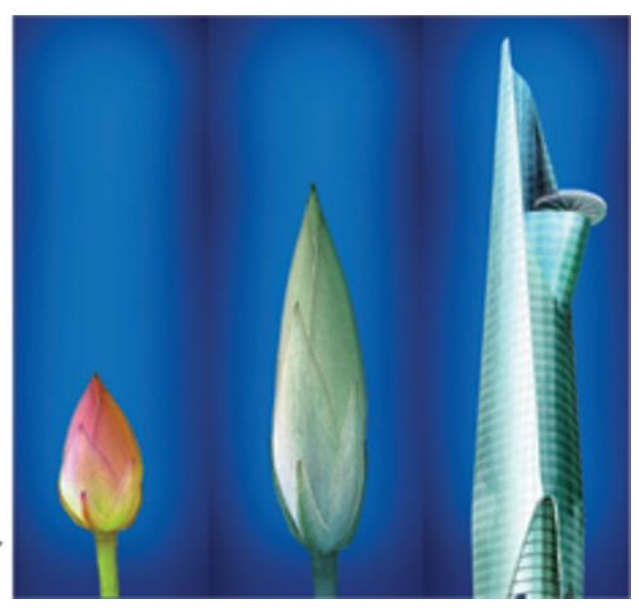

Fig. 6. The inspiration from the lotus bud.

\section{[ Source: AEWORLDMAP.COM][ Source: Bitexco ]}

Effective symbolism in architecture is rooted in the strongest and most universal experiences. Amongst these are religious beliefs and philosophical ideas, but also the perceptual dynamics of spontaneous symbolism deriving from daily experiences [18]. In Buddhism: The lotus represents refinement, mystery, contemplation and the cleanliness of the soul despite its earthly surroundings. [18]. The lotus plant's light, sweet fragrance evokes a noble spirit [18],with its white or pink petals and yellow stamen, the lovely flower discreetly grows up from the ground to proudly display its full beauty under the sun [18]. The lotus is considered to be the national flower, not just because of its indomitable spirit, purity and beauty, but also because of the admiration the Vietnamese people have for the flower.

The contradiction between form and function also has to be solved in this case by the developer as follows: Architecture today is necessarily "complex and contradictory to address the changing needs of a dynamic society" [19]. The city authority has allowed the tower to have a hotel and apartments to recover its capital in less time. But Mr. Vu Quang Hội had the foresight to see that the design will be more complex if the building has many 
different functions, so it was determined that the tower should only be financial, office and commercial to maintain the specific architectural curved lotus form as every floor must be different from the next. The world renowned architect Carlos Zapata from AREP (France) designed the delicate curved lotus flower form in a poetic discipline to enable Bitexco Financial Tower to become a memorable icon. As a retrogressive idea, representation can be flawed if it does not come from the architectural discipline itself [20].

The organization of the functional spaces that is to be in accordance with the lotus form of the tower. The Bitexco Financial Tower stands 262 meters high at the centre of the city's business district. It is a mixed-use building with more than 37,000 square meters of office space from the 7th to 65th floors highly occupied by finance organizations, banking, and multi-national corporations, and the six-story retail podium with around 10,000 square meters. Bitexco Financial Tower with its 68-story tower houses offices, shops, restaurants, and a helipad offering visitors an unparalleled city view from its Sky Deck. Around 464 square meters of space is available for a casual dining restaurant on level 50 and around 568 square meters of space is used for a fine dining restaurant on level 51, and approximately 300 square meters on level 52 for a VIP \& Bar Lounge. The building is highly occupied by finance organizations, banking and multi-national corporations.

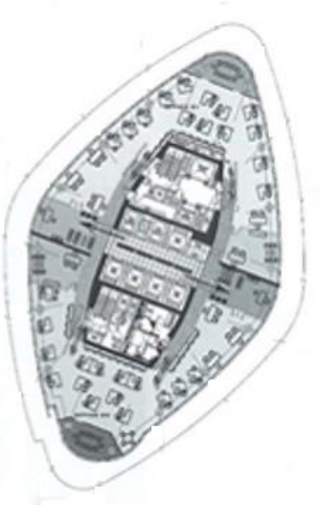

Fig 7: Typical floor plan belt walls. trusses .

[Source: AEWORLDMAP.COM] [Source: STRUCTURE magazine]

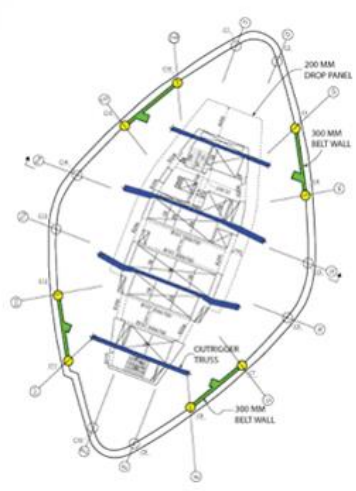

Fig 9: Outrigger

The Structural system and technological issues. To meet the challenge of technological complexity of the tower, top quality professional consultants from DSA Engineering (M\&E), LERA structural engineers and VNCC local partner, Hyundai Engineering and Construction Main contractor and other experts, partnered in the design and construction process. The office tower is essentially an all-concrete structure. Initially, a mixed system comprised of structural steel floor framing, composite perimeter columns and concrete core walls was developed [21]. Office floors are framed with reinforced concrete flat plate system.

The tower is tall and slender, core aspect ratio is 20 . An innovative structural design using concrete outriggers and belt trusses will stiffen tower against swaying motion. [21] The structure received an 'Excellence in Structural Engineering' award from NCSEA in 2011 and is currently the 124th tallest building in the world.

The weight of this tall building required very deep foundations. Poor soil conditions due to proximity to the Saigon River and the Mekong Delta require very long foundation piers. Comprehensive initial studies and subsurface explorations were performed to form a basis of the foundation design and to estimate foundation settlement. The tower foundation is a bored 
pile supported mat which effectively distributes the tower loads from the walls of the narrow services core over the extent of the mat [22].

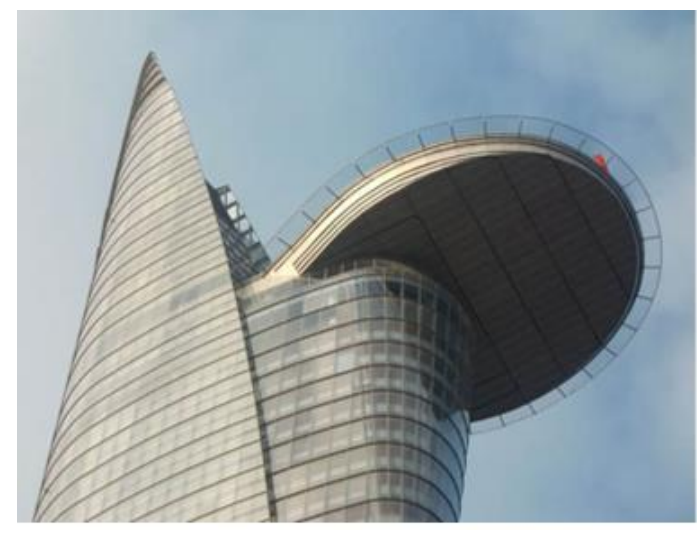

Fig. 10. The helipad of the tower. [Source: DESIGN.VN]

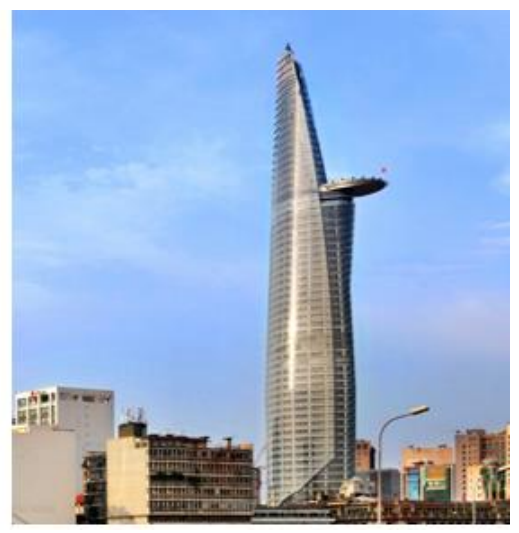

Fig. 11. View of the Tower. [Source: $D E S I G N . V N]$

The helipad was located on the southern side of the tower and suspended 191 meters above the ground, echoing the main form of the building with the shape representing a blossoming lotus bud. The total length of the axis of the helipad is 40 meters, including 18 meters extends into and 22 meters extend out from the structural system of the tower. The cantilever of the helipad was a challenge for the installation in the implementation process. The helipad central structures had to be special designed to accommodate and balance loads and forces, was constructed from more than 250 tons of structural steel and 4,000 ultra bolts. Before it could be hoisted up in parts to the 52th floor, the helipad structures had to be preassembled on the ground at a local factory.

\section{Conclusion}

Built at a time of unprecedented growth in the Vietnamese economy, the Bitexco Financial Tower is designed using both sophisticated form and high technology, which enables the tower to represent the energy and aspirations of the people and its form is an iconic embodiment of the new and dynamic Vietnam. Rising amidst several other buildings adapting the abstract geometrical glazed box form, the Bitexco Financial tower is distinguished notably because of its specific curved lines.

The case of the Bitexco Financial Tower revealed some of the considerable principles behind the process of the evolution of a shape generation strategy with respect to original traditional forms that gives a specific possibility of representation. That is only with the careful blending of both iconic form and objective can architecture succeed.

The result is that the tower was officially inaugurated on October 31, 2010. Bitexco Financial Tower has been listed as one of the 25 great skyscrapers - Icons of construction (by CNN - 2013); among the world's Top 20 iconic skyscrapers (by CNNGo - 2011); and has been awarded by NCSEA for "The excellence in structure engineering 2011" CNNGo recently ranked the Bitexco Financial Tower fifth in their listing of the world's 20 most iconic skyscrapers and is currently the 124th tallest building in the world.

\section{References}

1. 7 things to discover about contemporary architecture, BONE Structure (2014) 
2. S. Love, Elsevier, Journal of Anthropological Archaeology 32, 746-758 (2013)

3. S. Yurtkuran, G. Kırlı, Y. Taneli, Uludağ University, Faculty of Engineering and Architecture, Görükle, Bursa 16059, Turkey . Learning from Nature: Biomimetic Design in Architectural Education . 2nd Cyprus International Conference on Educational Research, (CY-ICER 2013).

4. N.A. Salingaros, K.G. Masden, International Journal of Architectural Research, 1 (2007)

5. P. Rezania, The Symbol of lotus in ancient world . Department of Cultures and languages of ancient Iran, Science and Research branch, Islamic Azad University, Tehran, Iran, 2011

6. M.A. Carrillo de Albornoz \& M.A. Fernández .The Symbolism of the Lotus .Article posted by India North, Aug. 26, 2014

7. Rev. Katherine Aryshta Dean. The Sacred Blue Lotus - Flower of the Gods. Excerpts from "Priestess of the Blue Lotus", 2017.

8. Cutemintran .Lotus - Vietnam's national flower, a symbol of divine beauty. Culturehttps:// cutemintran.wordpress.com Source from $\underline{\mathrm{Http}: / / \text { vietnam-online }}$

9. ADMINISTRATOR .One-Pillar Pagoda (Chùa Một Cột) posted on May 11, 2013.

10. Le Tien Tho, Deputy Minister of Ministry of Culture, Sports and Tourism. Lotus voted as Vietnam National Flower Vietnam online,2011.

11. Share Siwek The Sacred Lotus, Nelumbo nucifera. A Plant Study attended the 2007 Flower Essence Society (FES) Professional Course,2007.

12. Pham Ha . A Brief History of the Luxurious Pink Lotus, Vietnam's National Flower. Share on Twitter Jun. 22nd, 2017.

13. Er. Nishant Rana, Siddhant Rana . Structural Forms Systems for Tall Building Structures SSRG International Journal of Civil Engineering (SSRG-IJCE) - volume1 issue 4 September 2014.

14. B. Stafford Smith, Alex Coull, Tall Building Structures-Analysis and Design, John Wiley \& Sons, 2006.

15. Hi Sun Choi, Leonard Joesph, Neville Mathias. Outrigger Design for High-Rise Buildings, An output of CTBUH 2017Images Publishing, Victoria 3170, Australia,

16. Catrina Grünbaum. Structures of tall buildings Avdelningen för Konstruktionsteknik. Lunds Tekniska Högskola .Lund Universitet, 2008Rapport TVBK - 5156 (Department of Structural Engineering Lund Institute of Technology, Box 118, S-221 00 LUND, Sweden).

17. A. Hiller, B. Walters, (mentor) Honoris Thesis. Architecture Representation: Abstraction and Symbol within Design. Aprill 2012 .

18. C. Carter, Department of Philosophy, Marquette University. Symbol and Function in Contemporary Architecture for Museums,2010.

19. Buddhist studies. Buddha. BDEA/ Dharma Education Association \& BuddhaNet (Copyright 1999 - 2017).

20. R. Venturi, Iconography and Electronics: Upon a generic Architecturep 88. Cambridge, Massachusetts/London, England: MIT press, 1966.

21. P. Eisenman The End of the Classical: End of the Beginning, the End of the End". In Architecture Theory since 1968, Edited by Michael Hays: Cambridge Mass: The MIT Press, 1968.

22. W. Faschan, PE and.Trivedi, Nayan B, PEBitexco Financial Tower. STRUCTURE magazine, June 2009. 